\section{A915.34.01.08 - melon line resistant to leafminer (Liriomyza sativae)}

\section{Elaine Facco Celin ${ }^{1}$, Nádylla Régis Xavier de Oliveira ${ }^{1}$, Francisco Davi da Silva ${ }^{1}$, Valter Rodrigues Oliveira ${ }^{2}$ and Fernando Antonio Souza de Aragão ${ }^{1,3^{*}}$}

\begin{abstract}
Line A915.34.01.08 is a new source of resistance to Liriomyza sativae in melon. It was obtained by the genealogical method from a heterozygous plant with antibiosis type of resistance found within the accession $\mathrm{CNPH} 00$ 915. This line allows making introgression of this resistance in melon lines to develop commercial hybrids.
\end{abstract}

Key words: Cucumis melo, introgression, antibiosis.

\section{INTRODUCTION}

In Brazil, for more than two decades, at least $95 \%$ of melon production has been concentrated in the Northeast region, above all in the states of Ceará (CE) and Rio Grande do Norte (RN), between the Vale Jaguaribe, $C E$, and the Vale do Açu, RN (IBGE 2016). In this region, although the greatest production occurs from July to January, which includes the period of international exports, melon is grown throughout the year. Thus, consecutive growing allows the harvest of up to three crops per year, contributing to the agribusiness status of the melon crop. However, this also makes an increase in pests and diseases possible.

Plant health problems, in addition to limiting yield, make the crop less profitable, due to management costs. Among these problems, the leafminer Liriomyza spp. (Diptera: Agromyzidae) has been considered the main pest in melon (Guimarães et al. 2009, Nunes et al. 2013). The creation of mines in the leaves, caused by the feeding habits of larvae, is the main direct damage from this pest, the final outcome of which is reduction in fruit yield and quality (Araújo et al. 2007).

Although the melon breeding program of Embrapa began in the 1980s, the first studies aiming at genetic resistance to Liriomyza spp. began in the past decade. As of the end of the 1990s, the leafminer was no longer considered a secondary pest and reached the position of the main pest of the crop (Guimarães et al. 2009), and it stood out as the main plant health problem of melon in the Brazilian Northeast region (Oliveira et al. 2017).

Currently, although there are cultivars that show some level of tolerance to the insect, there are still no resistant cultivars on the market. Furthermore, few sources of resistance are reported in the literature (Nunes et al. 2013, Dogimont and Boissot 2016).
Crop Breeding and Applied Biotechnology 18: 215-220, 2018 Brazilian Society of Plant Breeding. Printed in Brazil http://dx.doi.org/10.1590/198470332018v18n2c30 \section{.}


Recently, in an evaluation of germplasm for resistance to Liriomyza sativae Blanchard 1938 (Diptera: Agromyzidae) at Embrapa Tropical Agroindustry (Fortaleza, CE, Brazil), a plant with antibiosis was selected within the accession CNPH 00-915, which belongs to the Melon Active Germplasm Bank of Embrapa Vegetable Crops. This plant was designated as $\mathrm{CNPH} 00-915(\mathrm{R})$ and was characterized as negatively affecting larval development. Selection was before flowering, which allowed self-pollination of CNPH 00-915(R), generating the first self-pollinating generation $\left(\mathrm{S}_{1}\right)$. Upon evaluating the $\mathrm{S}_{1}$ generation, segregation of resistance was observed, thus proceeding with the segregating population until obtaining a resistant line.

Therefore, the present study describes the process of obtaining the line A915.34.01.08 and the main characteristics of this new source of resistance to $L$. sativae.

\section{BREEDING METHOD}

The genealogical breeding method was used and, as of the $S_{1}$ generation, individual plants were selected whose families were evaluated, selected or discarded, in the successive self-pollination generations up to the $S_{4: 5}$ generation. To select superior plants in each self-pollination generation, laboratory trials were carried out in which the progenies were infested with the pest. In addition, to validate selection in the laboratory, the $S_{2: 3}$ and $S_{3: 4}$ generations were evaluated in the field. At the end of this process, the family A915.34.01.08 was selected as the resistant line since the resistance to $L$. sativae trait achieved homozygosity.

In each trial, samples of leafminer flies were collected for taxonomic classification of the species through morphological and molecular evaluations, carried out in the Agricultural Entomology Laboratory of the Federal Rural University of Pernambuco (UFRPE) in Recife, PE, Brazil. Only the species Liriomyza sativae Blanchard 1938 (Diptera: Agromyzidae) was identified.

\section{Laboratory trials}

The $S_{1}, S_{1: 2^{\prime}} S_{2: 3^{\prime}} S_{3: 4^{\prime}}$ and $S_{4: 5}$ generations were evaluated on 10/2014, 02/2015, 06/2015, 12/2015, and 04/2016, respectively, in a greenhouse and in the Plant Breeding and Genetic Resources Laboratory of Embrapa Tropical Agroindustry (latitude $3^{\circ} 44^{\prime} \mathrm{S}$, longitude $38^{\circ} 33^{\prime} \mathrm{W}$, and altitude of 19.5 meters) in Fortaleza, CE, Brazil.

In each generation, the plants were placed in polyethylene pots with 0.3 liters of substrate and kept in a greenhouse from sowing to infestation, with daily fertigation. When they achieved the development phase of three fully expanded leaves ( $\approx 22$ days after sowing), they were taken to the laboratory and placed in cages covered with voile cloth, in which eight adult flies (with 48 hours of life) per plant were released. The insects used were obtained from the stock maintained in the laboratory, derived from periodic collections taken from melon production areas in the Jaguaribe-Açu agricultural region, and multiplied in common jackbean, Canavalia ensiformis L. (Fabaceae).

After 24 hours of infestation, the plants were returned to the greenhouse. From the fifth to the tenth day after infestation, larval development was observed, and the plants were classified as either resistant (they did not allow larval development to the pupal stage) or susceptible (they allowed development of at least one larva to the pupal stage) (Figure 1). In the $S_{1}, S_{1: 2^{\prime}}$ and $S_{2: 3}$ generations, the number of mines per plant (intensity of infestation) was also evaluated, considering all the leaves, on the fourth day after infestation.

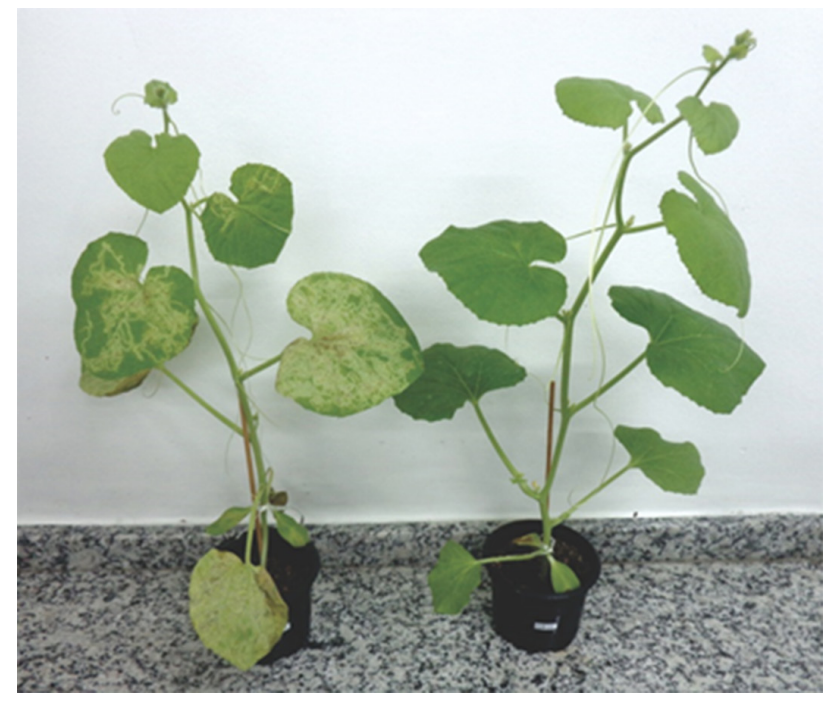

Figure 1. Susceptible and resistant lines after plant infestation by leafminers. 


\section{Field test}

The performance of resistance of the $S_{2: 3}$ and $S_{3: 4}$ families was also evaluated in the field, from 11/2015 to 01/2016 in

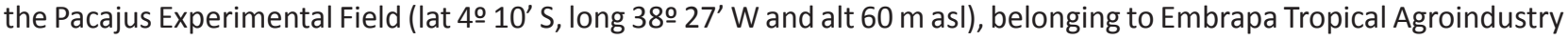
in Pacajus, CE.

The plants were transplanted to the field at ten days after sowing, at a spacing of $0.4 \mathrm{~m}$ between plants and $2 \mathrm{~m}$ between rows. Throughout the growing period, the drip irrigation system was adopted and fertilization was carried out daily by fertirrigation. No insecticide was used for pest control. The experiment was conducted in a randomized complete block design, with plots composed of 10 plants, with two replications. At 46 days after transplanting, the plants were evaluated, classifying them as resistant or susceptible (as described in the previous item).

\section{Selection strategy}

In the first trial, the $S_{1}$ resistant plants with the lowest number of mines per plant were selected, self-pollinated, and harvested individually, generating the $S_{1: 2}$ families. In the following generations, families with the highest proportion of resistant plants were chosen and, within families, the least infested resistant plants (smallest number of mines per plant) and those with mines of less than one centimeter. This selection strategy was repeated until obtaining a resistant homozygous family, that is, families with only resistant plants and progenies with the same phenotypic standard. Selections were made among the plants evaluated in the laboratory; however, in the final selection (in $\mathrm{S}_{3: 4}$ ), field data were also used in selection.

The plants selected in each generation were transferred to polyethylene pots filled with 5.0 liters of substrate in a greenhouse and were fertirrigated daily. Artificial self-pollination of the hermaphrodite flowers was performed at flowering; the flowers were emasculated before anthesis and protected with gelatin capsules to avoid contamination from pollen before and after pollination. These plants were cultivated until obtaining seeds, which were harvested individually to constitute the families of the next generation.

\section{DEVELOPMENT OF THE RESISTANT LINE}

In the laboratory, half of the $38 \mathrm{~S}_{1}$ plants evaluated had antibiosis lethal to the larvae of $L$. sativae and were classified as resistant. Ten of these plants generated the $S_{1: 2}$ families and all segregated, with the proportion of resistant plants ranging from 35 to $92 \%$. Three resistant plants with the lowest number of mines per plant were selected in the families with more than 70\% of resistant plants (A915.05, A915.09, A915.13, A915.24, A915.32, A915.34, and A915.35), except for family A915.18, which exhibited the greatest number of mines per plant $(7,3)$ among the resistant progenies (Table 1). Thus, $15 \mathrm{~S}_{2: 3}$ families were obtained. Plants of the $A 915.09$ family did not generate descendants.

In the laboratory, the $S_{2: 3}$ families exhibited from 65 to $100 \%$ resistant plants, except for A915.05.16, which exhibited only $13.3 \%$ (Table 1). These results were expected because in this generation, the stability (homozygosity) of the trait had not yet been achieved. The option was made to select four superior plants (the lowest number of mines per plant) within the four families with at least 95\% resistant plants. Thus, the families A915.34.01, A915.13.06, A915.24.10, and A915.34.13 were selected. In the fourth trial, $13 \mathrm{~S}_{3: 4}$ families were evaluated, among which progenies of the family A915.13.06 exhibited lower percentages of resistant plants (48 to 80\%); in contrast, the families A915.34.01.08, A915.34.13.05, A915.34.13.12, and A915.34.13.19 did not segregate; that is, all the plants evaluated were resistant (100\%).

These last two generations $\left(\mathrm{S}_{2: 3}\right.$ and $\left.\mathrm{S}_{3: 4}\right)$ were also evaluated in the field, where the proportion of resistant plants was less than the evaluation in the cage in most of the families. The biggest discrepancies in the proportion between plants resistant under controlled infestation and infestation in the field were observed in the families $A 915.05 .06(90$ and $0 \%)$, A915.35.03 (100 and 15\%), A915.35.30 (65 and 5\%), $S_{2: 3}$ generation; and in A915.34.13.06 (88 and 10\%), $S_{3: 4}$ generation (Table 1). These differences may be related to the genetic inheritance of resistance associated with environmental conditions and/or with the phenological phase of the plants. Nevertheless, the A915.34.01 family stood out in the field through exhibiting the greatest number of resistant plants (96\%), similar to that observed in the enclosure (95\%), and also through its progenies (A915.34.01.03, A915.34.01.08, and A915.34.01.17) being the most promising among the $S_{3: 4}$ families because all exhibited $100 \%$ resistant plants in the field and at least $88 \%$ in the cage. Among them, the A915.34.01.08 family did not exhibit segregation in either of the environments, with $100 \%$ resistant plants. 
Evaluation of the $S_{3: 4}$ generation was carried out first in the field and then in the cage and the information from both environments was used for selection of resistant plants. Thus, the $S_{4: 5}$ generation was obtained by selection and selfpollination of the superior plants of the families A915.34.01.03, A915.34.01.08, and A915.34.01.17. All the progenies of these families were resistant in the trial in the cage; therefore, the results of the $S_{4: 5}$ families were presented in bulk

Tabela 1. Evaluation of the five segregating generations from CNPH-A915R genotype for resistance to Liriomyza sativae

\begin{tabular}{|c|c|c|c|c|c|c|c|c|c|}
\hline \multirow{3}{*}{ Famil } & & \multicolumn{5}{|c|}{ Cage } & \multicolumn{3}{|c|}{ Field } \\
\hline & & \multicolumn{2}{|c|}{ Resistant } & \multicolumn{2}{|c|}{ Susceptible } & \multirow{2}{*}{$\mathbf{R}(\%)$} & \multirow{2}{*}{$\begin{array}{c}R \\
\text { NP }\end{array}$} & \multirow{2}{*}{$\begin{array}{c}S \\
N P\end{array}$} & \multirow{2}{*}{$\mathbf{R}(\%)$} \\
\hline & & NP* & $\mathrm{NM} / \mathrm{P}$ & NP & NM/P & & & & \\
\hline $\mathrm{S}_{1}$ & A915 & 19 & 21.4 & 19 & 45.3 & 50.0 & - & - & - \\
\hline \multirow[t]{8}{*}{$\mathrm{S}_{1: 2}$} & A915.05 & 20 & 3.7 & 2 & 8.0 & 90.9 & - & - & - \\
\hline & A915.08 & 8 & 4.9 & 15 & 11.2 & 34.8 & - & - & - \\
\hline & A915.09 & 29 & 4.3 & 9 & 10.7 & 76.3 & - & - & - \\
\hline & A915.20 & 15 & 5.7 & 21 & 12.1 & 41.7 & - & - & - \\
\hline & A915.24 & 32 & 5.8 & 6 & 14.7 & 84.2 & - & - & - \\
\hline & A915.32 & 23 & 5.3 & 2 & 7.0 & 92.0 & - & - & - \\
\hline & A915.34 & 29 & 6.0 & 9 & 8.0 & 76.3 & - & - & - \\
\hline & A915.35 & 32 & 4.3 & 6 & 8.0 & 84.2 & - & - & - \\
\hline \multirow{10}{*}{$\mathrm{S}_{2: 3}$} & A915.13.06 & 19 & 11.1 & 1 & 22.0 & 95.0 & 14 & 6 & 65.0 \\
\hline & A915.13.25 & 19 & 15.9 & 1 & 49.0 & 95.0 & 7 & 11 & 38.9 \\
\hline & A915.24.10 & 19 & 15.5 & 1 & - & 95.0 & 14 & 6 & 70.0 \\
\hline & A915.24.29 & 19 & 14.6 & 1 & 64.0 & 95.0 & 15 & 5 & 75.0 \\
\hline & A915.32.03 & 17 & 12.2 & 3 & 16.0 & 85.0 & 6 & 14 & 30.0 \\
\hline & A915.32.06 & 15 & 19.5 & 5 & 23.6 & 75.0 & 6 & 14 & 30.0 \\
\hline & A915.32.25 & 18 & 22.3 & 2 & 29.5 & 90.0 & 6 & 14 & 30.0 \\
\hline & A915.34.01 & 19 & 13.3 & 1 & 25.0 & 95.0 & 27 & 1 & 96.4 \\
\hline & A915.34.13 & 20 & 9.8 & 0 & 0.0 & 100.0 & 20 & 6 & 76.2 \\
\hline & A915.35.03 & 20 & 15.1 & 0 & 0.0 & 100.0 & 3 & 17 & 15.0 \\
\hline \multirow{8}{*}{$\mathrm{S}_{3: 4}$} & A915.24.10.05 & 22 & - & 3 & - & 88.0 & 13 & 7 & 65.0 \\
\hline & A915.34.01.03 & 13 & - & 1 & - & 92.9 & 10 & 0 & 100.0 \\
\hline & A915.34.01.08 & 25 & - & 0 & - & 100.0 & 20 & 0 & 100.0 \\
\hline & A915.34.01.17 & 22 & - & 3 & - & 88.0 & 20 & 0 & 100.0 \\
\hline & A915.34.13.05 & 25 & - & 0 & - & 100.0 & 21 & 3 & 87.5 \\
\hline & A915.34.13.06 & 22 & - & 3 & - & 88.0 & 1 & 9 & 10.0 \\
\hline & A915.34.13.12 & 25 & - & 0 & - & 100.0 & 14 & 5 & 73.7 \\
\hline & A915.34.13.19 & 25 & - & 0 & - & 100.0 & 17 & 7 & 70.8 \\
\hline \multirow[t]{3}{*}{$\mathrm{S}_{4: 5}$} & $\mathrm{P}^{+}-\mathrm{A} 915.34 .01 .03$ & 25 & - & 0 & - & 100.0 & - & - & - \\
\hline & P - A915.34.01.08 & 92 & - & 0 & - & 100.0 & - & - & - \\
\hline & P - A915.34.01.17 & 98 & - & 0 & - & 100.0 & - & - & - \\
\hline
\end{tabular}

*/NP= number of plants; $\mathrm{NM} / \mathrm{P}=$ mean number of mines per plant; $\mathrm{R}=$ resistant; $\mathrm{S}=$ susceptible; $\mathrm{R}(\%)=$ percentage of resistant plants; ${ }^{+} / \mathrm{P}=$ progeny. 
(Table 1). However, only the family A915.34.01.08 was considered to be homozygous for resistance since it exhibited only resistant plants and progenies with the same phenotypic standard. Observing the segregation of the population, the genetic inheritance of antibiosis seems to be dominant and controlled by more than one gene. Nevertheless, an analysis of generations should be undertaken to confirm the genetic inheritance of this resistance.

\section{CHARACTERIZATION OF THE RESISTANCE}

Resistance by antibiosis in line A915.34.01.08 is characterized by larval death soon after beginning to feed on the leaf mesophyll of the plant, resulting in very small mines $(<1 \mathrm{~cm}$ ) (Figure 2$)$. These mines, compared to those brought about in susceptible plants, are insignificant and, therefore, do not reduce the photosynthetic ability of the plant and, consequently, do not affect fruit yield and quality.

Moreover, through not allowing larval development, the resistant plants contribute to reducing the insect population in the field, as well as providing benefits to humans and to the environment through reducing the use of agricultural chemicals in pest management. This antibiosis must be associated with morphological or chemical defense mechanisms of the plant and, therefore, future studies should be performed with this new source of resistance.

\section{MORPHOLOGICAL CHARACTERIZATION}

The line A915.34.01.08 belongs to the Gália commercial type, of the reticulatus botanical variety. The fruits are characterized as rounded, reticulated (net-like), with a green skin at the beginning of development and yellow/orange skin when mature. The pulp has a greenish-white color when green and, when mature, it is salmon colored, with low soluble solids content and not very firm. The plant has medium branch length ( $\approx 1.5$ meters) and early fruit set $(\approx 35$ days after sowing), producing one or two commercial fruits per plant, with a weight between 0.7 and $1.5 \mathrm{~kg}$. In the field, it shows susceptibility to powdery mildew (Podosphaera xanthii), to the virus of melon yellowing-associated virus (MYaV) and some fruits crack during maturation.

Therefore, the line A915.34.01.08 is recommended for crosses in plant breeding programs that aim at introgression of resistance to $L$. sativae in melon.

\section{MAINTENANCE AND INCORPORATION OF RESISTANCE}

Embrapa Tropical Agroindustry is responsible for maintenance of the line A915.34.01.08 and for experiments of introgression of this resistance in elite lines or experimental hybrids of melon.

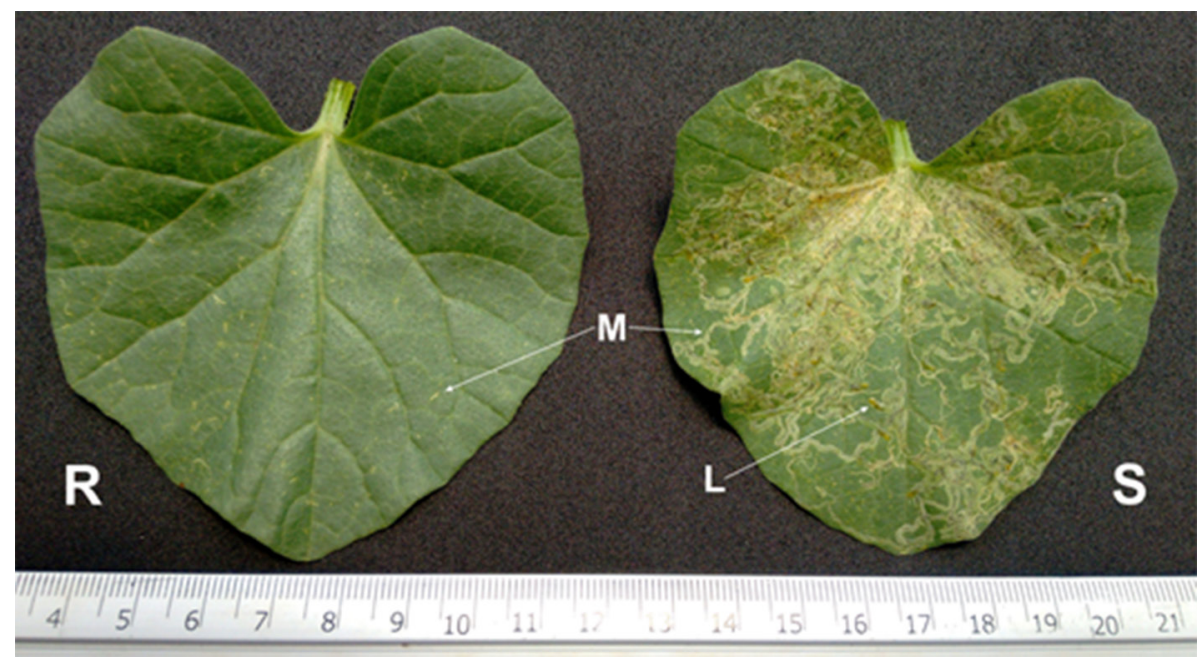

Figure 2. Mines (M) in leaves of the resistant line A915.34.01.08 (R) and of susceptible plants (S), showing development of leafminer larvae (L). 


\section{ACKNOWLEDGEMENTS}

National Council for Scientific and Technological Development - CNPq for a PhD scholarship to Elaine Facco Celin, an undergrad scholarship to Francisco Davi da Silva, and a research fellowship to Fernando Antonio Souza de Aragão (Process $n^{\circ}$. 311806/20147).

\section{REFERENCES}

Araújo EL, Fernandes DRR, Geremias LD, Netto ACM and Filgueira MA (2007) Mosca minadora associada à cultura do meloeiro no semiárido do Rio Grande do Norte. Revista Caatinga 20: 210-212.

Dogimont C and Boissot N (2016) Insect resistance in melon and its modification by molecular breeding. In Functional genomics and biotechnology in solanaceae and cucurbitaceae crops. Springer, Heidelberg, p. 199-219.

Guimarães JA, Oliveira VR, Michereff Filho M and Liz RS (2009) Avaliação da resistência de híbridos de melão tipo amarelo à mosca-minadora Liriomyza spp. Editora Embrapa Hortaliças, Brasília, 16p.
IBGE - Instituto Brasileiro de Geografia e Estatística (2016) Banco de dados agregados. Available at <http: //www.sidra.ibge.gov.br/>. Accessed on June 20, 2016.

Nunes GHS, Medeiros AC, Araujo EL, Nogueira CHF and Sombra KDS (2013) Resistência de acessos de meloeiro à mosca-minadora Liriomyza spp. (Diptera: Agromyzidae). Revista Brasileira de Fruticultura 35: 746-754.

Oliveira FIC, Fiege LBC, Celin EF, Innecco R, Nunes GHS and Aragão FAS (2017) Screening of melon genotypes for resistance to vegetable leafminer and your phenotypic correlations with colorimetry. Anais da Academia Brasileira de Ciências (in prelo). 